rate of two or three a month on the pattern of the Russian TU-16 aircraft, a few of which were supplied by the Russian government before relations between the two nations were soured in the late 1950s. Ever since the first Chinese earth satellite was launched in April 1970, however, it has been clear that the development of an inter-continental ballistic missile is on the cards In the past few months, the Chinese appear to have arranged that the missile-testing station at Shuang-ch'eng-tzu should be equipped to fire long-range missiles over a range that crosses India and reaches towards Zanzibar where arrangements are at present being made to monitor the final phases of re-entry. It is anybody's guess how soon these developments will lead to the installation of an effective striking force in mainland China, but there is very little doubt that by the late 1970s, China will be rubbing shoulders with the existing super-powers. Already the existing force of military aircraft should be sufficient for the Chinese to be able to deter the Russians from conventional military excursions to the East. What will happen to the agreements now signed in Moscow when there are enough inter-continental missiles in China to present the United States with a threat to be taken seriously? No doubt the clauses in the new agreements which allow the signatories at Moscow to break the restraints which they have voluntarily aocepted if circumstances should change would then be invoked. In short, there is a danger that the agreements will be eroded by the late 1970s unless the super-powers nave managed to reach an accommodation with mainland China before the end of this decade. Given the difficulty of negotiating limitations on nuclear striking forces which have become apparent at the SALT talks in the past few years, there is no time to waste. The most urgent corollary of Moscow is that both parties to the agreement should begin at once to persuade the Chinese that sooner or later they will have to follow suit.

\section{Russian Collaboration}

President NIXoN has brought back from Moscow not merely an agreement on ballistic missiles but a whole sheaf of agreements to collaborate on scientific and technical matters (see page 247). The question now is how these will function. The danger is that the longprepared and over-dramatic collaboration already worked out for the docking of space vehicles, one from each country, will either unreasonably dominate or will distract from the work that needs to be done in less spectacular fields of scientific research and development. The trouble, of course, is that it is very much easier to sign a joint declaration to do good works than to accomplish them. Over the years, the experience of the working of agreements on collaboration in science and technology between governments in the West and the Soviet government has not been entirely happy. For one thing, they have usually been implemented on too small a scale, at least where the exchange of people is concerned. Not nearly enough attention has been paid to the importance of short visits by people with something of urgent importance to communicate. Too much care has had to be exercised to ensure that the conditions of "mutual benefit, equality and reciprocity" which now crop up in the agreement between the United States and the Soviet Union are met to the bureaucratic satisfaction of both parties. And although there are welcome signs of willingness to collaborate on actual research, as for example in the exchange of research groups between CERN in Geneva and Serpukhov in Siberia or between the thermonuclear research laboratory at Culham and Professor V. Artsimovitch's group in the Soviet Union, very little has been done so far to plan research programmes which entail a division of labour and an exchange of information extending over several years.

As things are, several obvious opportunities for improvement exist. Thermonuclear research is one obvious field. But here it would be tactful if the Soviet and American governments were to recognize that they are not the only countries with a finger in this pie. Would it not be best if they were somehow to work out a framework for collaboration that could include other interested parties, the official organizations of Western Europe and even the smaller research groups elsewhere in the world, in India and Japan, for example? After all, there is a danger that too close or too exclusive a collaboration between the super-powers may merely exacerbate the sense which other nations enjoy that they are once more unreasonably and unfairly excluded. But is there not the strongest possible case for using the International Atomic Energy Agency at Vienna as a vehicle for enlivening this field for potential collaboration? And much the same is true of basic space research-although the Soviet Union and the United States have more to contribute to a common programme of research than the rest of the world put together, it would be a great mistake if they were now to set up bilateral arrangements for collaboration which give people elsewhere a sense of unreasonable exclusion. The difficulty, of course, is once again that it is harder to ensure that each party to an agreement on collaboration gets his money's worth in the framework of a multilateral agreement than if there is a simple bilateral exchange of information. This, however, should not deter the two governments now relaxing after their exertions in Moscow. After all, the wider the collaboration, the quicker will be the progress they can all expect.

\section{European Medicine}

ON the face of things, there should be greater difficulties in bringing about a coherent development of medical practice and research on a European basis than in rationalizing other branches of science and technology, which is why it is at once couragesus and imaginative that a group of professors in schools of medicine within the enlarged European Community has published a prospectus which calls for nothing less than the integration of the European medical community. The group has called itself the European Biomedical Research and Education Programme and appears to represent a great many of the European medical schools with a reputation in research as well as teaching. One of its complaints is that the present organization of European medicine and medical research is too much organized on national lines, with the result that medical care is not as good as it might be and that medical research is fragmented and in consequence unreasonably dominated by what happens 